\title{
Impact of Post Traumatic Stress Disorder on Employee Job Performance: Moderating Role of Spirituality
}

Qadar Bakhsh Baloch ( $\sim$ drbalochqb@gmail.com )

Abasyn University https://orcid.org/0000-0002-6686-6400

Verdah Qadar Baloch

Sourath Maher

Nadeem Iqbal

Syed Naseeb Shah

Mujahid Hussain

\section{Research Article}

Keywords: Post traumatic stress disorder, stress, employees performance, spirituality, terrorism

Posted Date: December 28th, 2021

DOI: https://doi.org/10.21203/rs.3.rs-1180786/v1

License: (c) (i) This work is licensed under a Creative Commons Attribution 4.0 International License.

Read Full License 


\section{Abstract}

The aim of this paper was to determine the correlation amid post-traumatic stress disorder (PTSD) and employee job performance with moderating role of spirituality among Police officials who experienced during the war on terror. Ninety seven personnel from Pakistan Security Forces, hospitalized as result of injuries in war against terror, were selected as study respondents and personally administered with the seventeen items questionnaire to measure PTSD symptoms. All the instruments administered to measure PTSD symptoms, employees' performance and spiritualty were adopted. Andrew F. Hayes Process model was used to test the hypotheses derived from the study's conceptual model as it was identical with the Andrew model (Hayes 2013) in which moderation is tested with one moderator that is spirituality. Correlation and Regression analysis were carried out by using SPSS. Moderation analysis checked the moderating effect of spirituality upon the relationship between PTSD and employees performance. The research concluded that PTSD negatively affects the job performance, however, spirituality reduces the negative outcomes of PTSD. The research found that the spirituality contributes positively to the psychological well-being of a person, thereby making one's self more robust to tremor and harrowing engagement and subsiding the negative impacts of PTSD. Managerial implications and future direction were also discussed.

\section{Introduction}

Post-Traumatic Stress Disorder (PTSD) is defined by Mayo Clinic (2013) as a mental health condition that is generally experienced directly by either observing or undergoing directly any terrifying event(s). Severe anxiety, bad dreams, flashbacks and overpowering thoughts about the event(s) are foremost symptoms of the disorder. Technically, it might be a reaction psychologically occurred after any event(s) which was extremely stressful for instance physical violence, natural disaster or a war combat. . It is a mental condition which affects a person who has had a very shocking or difficult experience such as fighting in a war and it is usually categorized by hopelessness, nervousness, recurring nightmares or recaps of that specific event (Learner's et al; 1980; Adam et al, 2019). The symptoms of PTSD may remain for months even years after the event(s) and usually affect the functioning of the entire body

Ever since the primitive era of orthodox warfare till the contemporary globally spread war against terrorism, humans have discovered to live on the bloodshed by developing an aspect of resilience. The psychological trauma experienced by humans as an outcome of either natural or human-created disasters calls for psychological interventions concentrating on the issue of PTSD (Umber and ljaz,2014; Adam et al, 2019). Effects of PTSD includes issues like, feeling separated, anxiety or generalized nervousness, and depression and their magnitude is directly associated with the level of severity of the exposure to the traumatic event(s) (Corrarino, 2008; McLeay, 2017; Meyer et al, 2019). Inexplicable tiredness, fatigue, sadness, feeling of misery, unlikely feelings of guilt, extreme state of worry, feeling of failure, loss of craving for work and food, sleep disorders, hopelessness and worthlessness, and symptoms related to bodily physique such as stomach pain and back pain are all signs of depression resulted in PTSD environment (Mental Health Foundation, 2006). Among other injuries, PTSD is very 
complex to understand, and difficult to tolerate and overcome, and in particular the one which is associated with the conventional war, and no doubt it becomes very hard for the soldiers or members of security forces those are out and exposed to the 'war on terror'.

The "Good stress" is felt when excited and is normally termed as "eustress," by the psychologists. Though pulse hormones flow accelerate during such stress as well, but there is no physical or psychological threat to it. Moderate stress kindles the production of a chemical named interleukins and provides the resisting immune system a speedy enhancement to guard against ailments. Therefore, in contrast to normal assumption, every type of "stress" cannot be termed as totally bad, rather a moderate degree of stress is necessary to reinforces readiness and rallies individual performance on challenging tasks (Ghazali,2004). However, unusually rise in stress flinches to erode performance, negatively affecting emotional intelligence, affect decision making ability, spoils work place mood, lowers productivity, and shut down self-regulation (Gates, et.al,2011; Matthewset.al, 2017; Janke et.al, 2018). Literature on stress and performance unanimously endorses the significantly inverse relationship between the Stress disorder and employees as well as organizational overall performance with deteriorating work quality, increasing errors, and absenteeism. The literature also identifies, amongst the suffering employees, the tendency of higher degree of turnover intensions, deteriorating health with ailments like anxiety, emotional disorder; work life imbalance; and psychological state of hopelessness etc.( Ghazali,2004; Singh, Y., \& Sharma, 2012; Janke et.al, 2018). Empirical research studies investigating post trauma effects found that a PTSD affected may experience symptoms such as; regrets, cynicism and self-betrayal that hampers timely reclamation of sound health, requiring detailed psychotherapeutic attention (Yager,\& Kay, 2020). Ciocca,et.al, (2015) suggest continuous and intimate psychological support for these patients to help them to positively recover from PTSD.

Finding spiritual or religious practice to cope up with stress has been often a commonly adopted stress management strategy. Because, spirituality provides reliably believed alternative to the person that dependence on God helps conceding fears and concerns. Bourne \& Watts (2011); and Canda et.al, (2019) note that spiritual performs such as praying, reflecting, meditating, joining a church or mosque sermon or travelling in nature, cultivate positive changes in ones perceptions about life, attitude, and behavior needed to contest sadness, hopelessness, and depression. Kent (2020); and Kent et.al, (2020) contend that prayers of the people having secured perceptions about God, as sincere and earnest loving, are result with optimistic psychological outcomes that cope up stress to a considerable degree. Stress amongst spiritually void people is converted in to Spiritual distress where the subject is unable to find meaning, amity, relief, strength, or connectivity with life. . Bourne \& Watts (2011) and Kent (2020) suggests that Spirituality allows people to overcome stress.

Bodily injuries sustained by the soldiers during combat cause both; physical and psychological burdens. Besides, the physical wounds of war, the soldiers are exposed to manifold combat experiences such as, seeing friends amongst serious casualties (injured or killed), missing comrades, and charging enemy on 
the face of relentless fire or bearing barrages of enemy fire. According to Grieger, et.al, (2006), "interaction across time of wound, battle exposure, discomfort, doubts about physical recovery, and apprehensions over long-term disability or dysfunction, availability of sustained medical care or otherwise, and wanting social supports results in a intricate option of ailment and retrieval". Psychological stress of 'war on terror' is relatively different that of conventional war, because in case of 'war on terror', the enemy is hidden, may be from within and not limited to frontiers with incomprehensible results. Whereas, in conventional war the enemy is visible, operating along defined borders and the results delivered become source of accomplishment thereby minimizing the extreme effects of PTSD as compared to those traumas of 'war on terror. Since the September $11^{\text {th }}, 2001$, paralleled to the role played by NATO forces and US troops in Afghanistan and Iraq, Pakistani forces are also facing the 'war on terror' countrywide for more than a decade now especially in the tribal areas and province of Khyber Pakhtunkhwa.

The veterans and the families of the injured or dead of the Pakistan security including Police, Frontier Corps, and Rangers or military including have been consistently facing the trauma during the war on terror. The negative impact of PTSD has been apparent on one grounds or the other on the job performance. It is therefore area of concern for researchers to find out the factors which are playing a role to develop Counterproductive behavior of employees. It is also important to find out factors which are helpful to improve the performance of employees. Post-traumatic stress disorder (PTSD) is understood as a deferred reaction to an abnormal, traumatic life experience like war, terrorism, accident, a natural disaster, or any kind of physical, emotional or psychological abuse (Miller et al, 2012, 2014). The literature suggests that spirituality is considered to be very helpful to people in times of crisis, trauma and grief (Houghton et al, 2016; Worden, 2018; Kalantari \& Khalili, 2018; Garg, 2020). A latest systematic review articles in the Journal of Traumatic Stress also observed similar results that spirituality is very reassuring to people when they are confronted with situations of crisis, grief and trauma (Weaver et al, 2003).

\subsection{Research Question:}

Aim of this study is to investigate the effects of PTSD upon employees' performance of Pakistan security forces personals and how does spirituality moderate this relationship. Therefore the study focused on the following objectives:

a. To examine 'impact' of PTSD on the employees' performance of the police and personnel other security forces having fought war on terror in KP and around.

b. To find out the moderation effect of spirituality on the association of PTSD with Perceived Job Performance

\section{Literature Review}

Organizational accomplishment is not simply the outcome of an well thought-out organizational strategy, rather, it is a creation of its employees' productivity and performance (Amabile et al., 2004; 
Cadwallader et al., 2010) to meet the firm's organizational objectivesLatest literature proposes that positive attitudes at workplace, work engagement, organization and management support, employees well-being, and task performance are directly associated with engaging employees (Baffoe, 2018; Kim \& Kim, 2020). Loving-kindness meditation study for veterans with posttraumatic stress disorder (PTSD) was found safe and promising in overcoming symptoms of PTSD and delivering workplace performance (Kearney,et.al, 2013). Employee performance is direct outcome of the employee workplace engagement. Whereas, quality and productivity of the employee engagement hinges upon physical and psychological health that HR managers must incline to focus upon (Bedarkar \& Pandita, 2014).

Employee performance denotes fulfilment of workplace effectiveness, quality of work coupled with efficient productivity. Employee's value in the organization is directly related to corresponding degree of his contributive performance (Bashir and Ismail, 2010; Qamar \& Baloch, 2011; Baloch,et.al, 2016). Stress amongst employee, if surpasses it moderate level, effects employee's performance negative side of the continuum. Because, stress leads to tiredness, and feeling of fatigue, lowers the motivation level, frustrates workplace harmony and a drops in professional passion and eagerness. These all psychological and physical reflections considerably influence performance towards negative side of the productivity. Stress has been shown to adversely affect organizations wherein staff who report higher levels of stress have lower job satisfaction, increased turnover, increased absenteeism, and lower productivity (Baloch, 2009; Vijayan, 2017; Khalid et.al, 2020)). Employees stress equally erodes organization performance because of absenteeism, turnover intentions, distress and, lower morale, intensity of complaints and conflicts, physical and psychological breakdown of employees (Baloch, 2009; Khalid et.al, 2020)

Employee engagement has three interconnected elements i.e. behavioral, emotional and cognitive elements (Bobek, 2009; Shuck, 2014; Hanif, 2015). The behavioral element is a value added element and it has discretionary efforts such as, internal motivation and devotion to fulfill tasks, commitment towards the organization and its goals, and employing extra time. Emotional component focuses on the perception of employees regarding the attitudinal factor i.e. either the employees possess positive or negative attitudes towards their management and the organization itself. The cognitive element observes the beliefs of employees about the work environment, and about the top management of the organization. (Barney and Wright 1998; Pfeiffer, 1998; Hanif, 2015). All these gives support in managing combat stress and PTSD compressed environment at workplace thereby maintaining the affected performance of the employees.

\subsection{PTSD Framework}

Stress is sensation of expressive reaction or corporal pressure that is normally defined as the higher degree of overwhelmed feelings. In medical language stress is body's reaction to physical, mental, or emotional pressure. American Psychology Association defines stress as any type of change that predicts physical, emotive, or psychosomatic tension or strain. Its body's reaction to everything that entails 
responsive attention or action. No one is free from stress rather everyone practices stress to some degree on one pretext or the other. Stress roots changes in the body with increase in blood pressure, acceleration in heart rate, and blood sugar levels. Stress may be positive or negative. Positive stress helps energize motivation to accept challenges or meet targets or deadlines. Negative side of the stress represents state of inability in coping with outcome of incontrollable pressures confronted with and marks one feel frustrated, irritated, tense or nervous. Negative stress results in to the development of feelings of frustration, hopelessness, nervousness, anxiety, annoyance, anger, sadness or depression.

PTSD has been defined as an ailment or disorder that is sequential follow-up of life-threatening event experienced by an individual or serious injury resulting in physical or psychological of incapacitation of function life or hopelessness. PTSD symptoms, vary from person to person and time to time, are generally grouped into unpleasant memories, negativity in mood, emotions and thoughts, and changes in physical and psychological reactions. Posttraumatic stress disorder (PTSD) is a psychiatric disorder that used to be known in the past as "shell shock" or "combat fatigue" during World War era. PTSD not happens to combat veterans and may occur in people of any society, or culture, and gender of any age. It happened to occur in people who have witnessed or faced a shocking happening that may be a natural tragedy or catastrophe, or manmade such as a fatal accident, a terrorist attack threatened with death or sexual violence.

PTSD is an anxiety disorder that occurs in response to an extreme traumatic event in somebody's life which may include military combat, terrorist attacks, violent personal assaults, natural disasters or serious accidents. People having experienced PTSD have distressing feelings that usually continue harassing for longer duration of time even after the traumatic incident occurred. The feelings reflect state of hopelessness, despondency, anger; and estranged from other people. PTSD, if not properly treated, is questionable to dissolve and results in to enduring pain, prolonged depression, drug addiction sleep loss, hampering a person's ability to work and interact with others.

Outlining the track history of PTSD framework, Parry-Jones et al (1994) discovered that "abnormal stressors have been featured in all the societies from the earliest civilizations". Although stressful events have existed in the history of mankind, but the PTSD is "an enduring condition that was codified in the contemporary diagnostic categorization, and depicted by various names like 'shellshock' and 'railway spine' etc. (Jones et al, 2003). The study of PTSD gained momentum in the period of post WW-II when various studies were published on "Combat Fatigue" by Josiah Macy, Jr. Foundation. The publications included "Personality Disturbances in Combat Fliers" (Levy, 1945), "How can the flight surgeon better treat anxiety? and; "Notes on Men and Groups under Stress of Combat" ?"(Wright, \& Bond, 1945). The classification of PTSD became more amplified, when environmental stress was studied parallel to the combat related stress, and "PTSD first emerged as an operational diagnosis in "DSM-III" (1980), which was modified into "DSM-III-R" (1987), and into “DSM-IV" (1994)( Parry-Jones et al,2006. 
Extreme fear, ineptness, desperateness, and decreased energy

levels are hallmarks of the disease and can affect the overall functional aspects of a person's life (Bender, Morey,and Skodol, 2011) and it is very common for other conditions; depression, anxiety, or substance abuse to occur along with PTSD. The symptoms of PTSD immediately after the traumatic event may remain hidden until months or years, having following indications:

a. Re-Experiencing Symptomsi.e. Becoming upset when defied with a traumatic prompt or thinking about the trauma when you are attempting to do something else,

b. Avoidance and Numbing Symptoms i.e. detachment from people and places leading to social isolation, and Arousal Symptoms i.e. sleeplessness, hyper-alertness to danger.

\subsection{Employees Performance}

Performance' is a sequence of controlled actions of employees that leads to the achievement of organizational goals, and the actions could be measured on individual level. Murphy (1989); Campbell (1994) and Iqbal et al (2015) defined 'performance as a set of employees' behaviors that facilitate advancement towards organizational goals and leadership style plays very decisive role in it. High level of motivation, espirit de corps, and true empathy, dedication for martyrdom, divine reward, and strong belief in religion plays a significant role in improving the employees' performance against the occurrence of PTSD in combat environment (Wagner, 1994; Newsome, 2003; Silke and Brown, 2016). The eminence of decisions depends on the positive or negative attitude of the front line employees. If the employees have a high level of satisfaction towards their organization, they would exhibit an added role of behavior, and will also try to put a good impression of their organization acting as a role model.

Brown et al (2016) and Verhage et al (2018) suggest employees' involvement in decision making process. Participation in decision making enhances employees' commitment that directly persuade their performance for the overall benefit of the organization. Performance of is optimized by their high level of motivation. Motivation is among the most studied element as it presumes that a satisfied employee displays enhanced performance that benefits the overall performance of the organization and its growth. Baloch (2007) suggests that satisfied workers are more productive. Organizational performance is directly hinges upon the individual performance. Therefore, employee performance has always been an important variable in examining PTSD, during WW-II and the recently conducted War on Terror in Iraq and Afghanistan (Schnur et al, 2009; Tsai et al, 2012; Mobbs and Bonanno, 2018).

\subsection{Security Forces Personnel Performance Relationship with PTSD}

PTSD is found as a common occurrence among military veterans, as more than one million veterans from the Vietnam's war had experienced combat PTSD, almost half of them having the symptoms as of 1990 (Kulka et al;1990; Weiss,1992). According to "National Co.," morbidity survey of Korean conflict veterans and WW-II, about $58 \%$ of the male veterans were diagnosed with trauma which was combat 
related and was related to the most stressful trauma event (Kessler et al, 1995; Kessler, 2000).). Study conducted by Zatzik et al (1997) indicated that those male veterans, who were identified with the symptoms of PTSD, were three times more probable to be out of work as compared to those who were not affected by PTSD. PTSD has been strongly connected with reduced performance at work among veterans of Vietnam. Savoca and Rosenheck (2000) discovered that lifetime effects of PTSD were associated with the fact that current employment probability for affected veterans was $50 \%$ reduced. Seal et al (2007) while investigating PTSD among US war veterans returned from Iraq and Afghanistan after spending two years in War Theaters found "103 788 out of 165351 veterans suffering with Mental Health Disorders. Elbogen, (2014), while investigating PTSD, found a distinct surge in violence and physical aggression in veterans of War on terror in Iraq and Afghanistan.

The post military service rehabilitation cum social integration through absorption in civilian service is one of the most challenging factors for the post-service well-being and success of the veterans and especially more telling for those who are affected with the PTSD (Vogt et al, 2017; Kintzle and Castro, 2018). Veterans effected with PTSD generally face problems at workplace and ethically it is expected that employers shall recognize the challenges faced by the affected employees and cooperate to support affected employees to recover through reasonable adjustments. Employers in each organizations shall acknowledge that war veterans from security forces are an imperative human capital, each one of them hold valuable knowledge, skills, abilities, experience and endurance (Simpson \& Sariol, 2018). Hence, a systematic and articulated integration of war veterans, with more emphases on PTSD, in to civilian employment market shall be taken, not only as corporate social responsibility, but also as a most promising linchpin for the job market if judged on the applied side of the "Diversity principles"(MacLean, 2017).

Religious philosophies and observances (spirituality) are acknowledged as traditional means of developing individual beliefs, values that define meaning to their life. Even, health professionals are recognizing spirituality as a primary human dimension for psychological balancing besides other social, emotional, physical, and cognitive aspects, as significant coping measures from psychological and stress disorder. Spirituality is the inner spring of wisdom that is mirrored in human oriented ethics and performance oriented behaviors. The values of spirituality include sympathy, empathy, kindness, modesty, imagination, and knowledge. According to Paramahansa Yogananda, Indian monk and guru of meditation and Yoga, "Spirituality is the infinite reservoir of wisdom. Each human is a channel through which that divine wisdom is steadily flowing" (Guillory, 2000). Workplace spirituality lessens stress level, and provides an all-inclusive umbrella that embraces the totality of work-related activities encompassing diversity, performance, workplace engagement, work life integration, creativity, or imagination. Spirituality constructs positivity amongst individuals and helps cultivate employees into a better humanoid (Houghton et al, 2016). Spirituality when linked with religion gives birth to a strong and better citizen who always believes in helping others, and giving back to society (Kalantari \& Khalili, 2018).Furthermore, a higher level of spirituality is correlated with lower level of post-traumatic syndromes, and significantly positive association with high degree job satisfaction and contentment that subdue pains, anguish and nervousness, despairs and mental disorders to a considerable extent (Connor 
et al, 2003; Miller et al, 2012; Houghton et al, 2016; Milliman, Gatling, and Kim, 2018 ). Hence, organizations gifted with the culture of spirituality support shape affirmative culture, healthy environment, principled and considerate leadership for the workforce marked with PTSD syndrome (Garg, 2020).

2.6 Conceptual Frame Work \& Development of Hypotheses: Following conceptual framework derived from the review of related literature and preceding discussion thereof as diagrammatically exhibiting association between security forces related PTSD with the their employees performance:

Figure. 1: Conceptual Framework

Hypotheses: A set of hypotheses to be tested by this study is given as follows:

H1: Post traumatic stress disorder directly negatively affects the Job Performance.

H2: Spirituality moderates the relationship between Post Traumatic Stress Disorder and Job Performance.

H3: Spirituality directly positively affects the Job Performance.

H4: Spirituality directly affects post-traumatic stress order.

\section{Research Methodology}

To pursue its research objectives, the study was conducted in two stages. The stage one was prelude to the main study that conducted to check the consistency of the instruments through a pilot study and necessary modifications were incorporated accordingly. In stage two the main study was undertaken through a survey research. This explanatory study surveyed the properties of the PTSD Checklist scale commonly known as PCL-5 (Weathers et al., 2013). Self-administrated questionnaires, to measure PTSD, Employees Performance and Spirituality, were distributed amongst the veterans of war against terror $(n=97)$ from Pakistan security forces including Police and admitted in major civil and Military hospitals at Peshawar and Rawalpindi after returning from War. Correlation, Regression and moderation analysis was carried out by using SPSS. Moderation analysis is tested. The PCL-5 test scores demonstrated good internal consistency for PTSD $(a=.77)$, Employees Performance $(\alpha=.80)$ and Spirituality $(\alpha=.73)$ as tabulated in table no. 4.1 below.

\section{Data Analysis}

\subsection{Results}

Table No. 1: Validity and Reliability Values of the Instrument

Table No. 2: Descriptive Analysis

Table No. 3: Correlation Analysis 
The Table 4.2 and 4.3 above describes the descriptive statistics and correlations analysis of four variables i.e.; PTSD, spirituality, perceived performance, and age. The means for each variable showing that levels of post traumatic disorder range from moderately high to highest level. While the correlation coefficients values indicate that the data have not affected by co-linearity problem (Hair et al., 2006). The relationship between post-traumatic stress disorder and perceived performance is negatively and significant $(r=-.332, p<0.01)$ and The relationship between post traumatic disorder and spirituality is negative and significant $(r=-.494, p<0.01)$. The relationship between spirituality and perceived performance is positively and significant $(r=.487, p<0.01)$. The relationship between age and posttraumatic stress order is positively and significant $(r=.227, p<0.05)$. (See table 4.9).

\section{Table: 4: $\quad$ Model Summary}

4.2. Findings: For testing the hypotheses the research used the Process introduced by the Andrew F. Hayes (Hayes, 2013; 2017). The study model shows that moderator effects the path so one interactions occurs in the results. Therefore, the study confirms that Spirituality moderated the relationship between post traumatic and employees performance. The findings derived from the tabulated results are:

a. The table no. 4.4 above shows that post-traumatic stress disorder directly negatively affects the Job Performance results $\beta=.-.0708, t(93)=6.15$ and $p=0.0006$ which confirms that there is negatively significant direct effect of post-traumatic stress and employee performance so results do accept the hypothesis $\mathrm{H} 1$.

b. The Table no.4.4 above shows results for interaction_1 (check the path between post-traumatic stress disorder and employee performance), $\beta=.0706, t(93)=6.15$ and $p=0.0006$. Hence, the results do accept the $\mathrm{H}-2$ i.e.; Spirituality moderates the relationship between Post Traumatic Stress Disorder and Job Performance.

c. The table no. 4.4 shows that spirituality directly positively affects the Job Performance. $\beta=.2805, t(93)$ $=3.3115$ and $p=0.0003$ which confirm that there is significant direct effect of spirituality and employee performance so results do accept the hypothesis $\mathrm{H} 3$.

d. The table no. 4.4 shows that Spirituality disorder negatively directly affects post-traumatic stress order. Which confirm that there is significant direct effect of spirituality and employee performance so results do accept the $\mathrm{H}-4$.

e. The value of adjusted $R$ square (.25) indicates that 0.25 of the variation in job performance is explained by PTSD. The higher value of regression sum of square compared to the residual sum of square indicates that the model is capable to capture most of the variation in the dependent variable. As the F statistics (6.6351) is significant (.004) so it can be concluded that the model is fit for making prediction about the relationship between PTSD and job performance.

\section{Discussion And Recommendations}


This study was aimed to investigate the impact of Post-Traumatic Stress Disorder -PTSD on the employees' job performance as well as the moderating impact of spirituality on the relationship of PTSD and job performance of the personnel of Pakistan security forces including Police combated the War against terror. Resulst showed that PTSD negatively affected the job performance $(\beta=-.0708, p<.001 ; r$ $=-.332, p<.01)$. These result supported the hypothesized relationship. These findings are aligned with the previous studies e.g. Kazmi et al (2014), Parry-Jones et al (1994), Waheed, Jamal and Riaz (2015). This can be explained such that when security forces personnel became victim of PTSD there psychological well-being is affected negatively. Subsequently, this cognitive phenomena is converted to psycho-somatic / physical problems and hence the performance of the personnel is affected negatively.

Hassan et al (2016); Houghton et al, 2016; Milliman, Gatling, and Kim, (2018) and Grag (2020), all confirm that the work place spirituality holds significantly positive relationship with job satisfaction, add in to the employees contentment level and down plays the negative feelings of employees under stress. This study finds out that spirituality moderated the relationship between PTSD and job performance (table no.4.4). Previous research studies of Koeing, 2009; Houghton et al, 2016; and Grag (2020) support the findings that religiosity and spirituality lessen the negative impacts of cognitive and psychological disorders i.e. depression, anxiety, frustration, and emotional exhaustion etc. It was hypothesized in the study that spirituality lowers the negative impacts of PTSD on the job performance. Results of this study confirmed this and thus supported the hypothesis. Milliman, Gatling, and Kim, (2018) conclude that spirituality amongst individual or in organizational culture inculcate motivation for performance and minimize negative perceptions or pains developed during work.

This study gave a brief description of PTSD and its effects on the performance of veterans who have been involved in war zones. PTSD and job performance especially in war zone are strongly linked together. This study can be concluded in way that although PTSD negatively and badly affected the job performance of Security forces personnel having subjected to the effects of War against terror however, their negative outcomes can be lessened by the spirituality. The possible explanation for this fact may be that the spirituality contributes positively to the psychological well-being of a person, thus making one's self more resilient to traumatic absorption.

\section{Study Limitations}

The study was limited to the security forces personnel including Police who were either, owing to their PTSD, admitted in hospitals or returned to peace location after recovery from the physical and psychological rigorous of war against terror. In addition, the study also holds following limitations:

a. Use of self-reported methods of PTSD and depression, though the instruments used were well validated through number of research studies in the past.

b. Across-sectional study, thus causation cannot be established with accurate conclusion.

c. The low representation of female combat soldiers in Pakistan's security forces, and the exclusion of veterans with severe mental damages limit the research findings to generalize to other populations. 
d. Deficiency of an objective measure of injury sternness or social supports that might have added to the recovery or deteriorating of symptoms in post hospital's discharge period.

Keeping in mind the above mentioned limitations, the future researchers shall employ more rigorous research design e.g. longitudinal design and sample inclusive of veterans in the process of rehabilitation / integration in the society after getting discharged from hospitals. The data collection may also involve other sources e.g. personal and war diaries, citations and situation reports, interviews, focus group discussion. The link between PTSD and veteran employee performance in war zones for the war on terrorism in Pakistani tribal areas, and Afghanistan have opened up new avenues for future research i.e. extending it to IDPS during their displacement and rehabilitation phases. Furthermore keeping in view the polarization of views of the masses on the causes and effects of the war against terror there is dire need of measuring the socio-cultural effects on nation psyche in post war scenario.

\section{Study Recommendations}

Though War on terror is apparently concluded but the sleeper cells of terror groups are still active and news of clandestine attacks on security forces in tribal areas and Balochistan astride Afghanistan border keep appearing with soldiers seriously wounded or killed. Threat of simmering debris of war is looming until successful culmination of Afghanistan peace process is realized. Furthermore, Pakistan is not only exposed to manmade disasters but also exposed to natural disasters which leave extremely affected in the past with lasting impact on our socio-economic and socio-psychic national profile. With the continuity of occurrence of traumatic exposure (though comparatively lesser in magnitude) has added in to the want of developing more understanding to the theory of resilience. The notion of resilience comprehends psychosomatic and biological individualities that deliberate guard against the psychopathological issues on the face of PTSD. The study recommends for administering high degree of social support to the veterans having suffering from PTSD phenomenon. Some of the suggested measures are:

a. The PTSD subjects shall not be left unattended and in isolation. All efforts shall be undertaken to keep all horizontal and vertical lines of communications with special emphasis on social support and dialogue on the topics leading to psychological healing.

b. Structure conducive work and living environment that help them to change their bitter experiences of physical and psychological injuries. Besides, social and health security, it may call for socioeconomic packages to ease out their post retirement livings.

c. Rebalance family and work schedule and regularly follow the commonly advised stress control health measures programs including; regular and systematic stress control exercises, associate in the company of supportive nature people with positivity of mind, sleep enough, eat well and avoid Alcoholic drugs, find out time for hobby and pets, and undertake meditation practices. 
d. Security forces shall incorporate PTSD inoculation training during peace time with long spells of physical and psychological exposures so as to build on their individual and group resilience.

e. Religion motivates people and provides a structure that offers a group of people to bond with similar beliefs and values. The religious belief impacts the individual's approach towards the life and shape their mental and socio-psychological leaning. There is plethora of literature that reinforces that religiosity and spirituality helps to disassociate from evils, theft, abusive behavior, atrocities with weeks, controls tendency to suicide, alcoholism and drug use. Therefore, soldiers shall be subjected to the frequent interactive sessions with the religious scholars to strengthen their belief to fight for RIGHT against social menace damaging their society and its socio-economic wellbeing. The enhancement in their degree of spirituality would multiply their resilience to manifold and face the scourges of when trusted upon them or their society.

f. A variety of pragmatic exercises for learning and training of spirituality amongst soldiers across ranks and files should be made regular feature of their training programs. These learning classes or exercises may encompass appropriate techniques such as, lectures on the purpose of human life and humanity and hereafter, values of good, stories of religious ventures, meditation, silent prayers etc. The learning material shall be drawn from a variety of religions related to the soldiers. In addition, outside "practice" of prayer and meditation exercises. The group members should be facilitated to attend the spiritual meeting and religious prayers/ gatherings of their respective religion.

g. The ultimate aim of all coping strategies is to build a strong sense of hope, and a more realistic balanced view of the evil and good. Facilitating PTSD patients' to re-connect with the roots of their faith or discovering new avenues of religious expression may provide ongoing meaning and comfort.

h. Having located in one of the most vulnerable to natural disastrous regions of the world Pakistan need to prepare itself to understand and appropriately counter the impact of the disaster PTSD on our national fiber. In this context it is recommended that Pakistan should set up a Board of posttraumatic stress disorder at national level to ensure effective management of PTSD. The Board should launch a study forum to explore and analyze the long-term PTSD effects of war against terror as well as natural disasters upon our national psyche. The research shall be conducted by a team of experts and researchers pooled up from the National Institute of Disaster Management (NIDM) National Institute for Clinical Psychology (NICP), National Defense University (NDU), and Drug Rehabilitation Institute (AFIRM) Armed Forces and other researchers in the field.

\section{References}

1. Adams, S. W., Bowler, R. M., Russell, K., Brackbill, R. M., Li, J., \& Cone, J. E. (2019). PTSD and comorbid depression: Social support and self-efficacy in World Trade Center tower survivors 14-15 years after 9/11. Psychological trauma: theory, research, practice, and policy, 11(2), 156

2. Amabile, T. M., Schatzel, E. A., Moneta, G. B., \& Kramer, S. J. (2004). Leader behaviors and the work environment for creativity: Perceived leader support. The Leadership Quarterly, 15(1), 5-32 
3. Baffoe, A. K. (2018). Corporate Social Responsibility, Employee Engagement and Job Satisfaction in Leading Ghanaian Companies (Doctoral dissertation, University of Ghana)

4. Baloch, Q. B. (2007). Managing Human Resource: Is There a Lesson for Pakistan in the Japanese Management Style. Journal of Managerial Sciences, 1(1), 1-25

5. Bedarkar, M., \& Pandita, D. (2014). A study on the drivers of employee engagement impacting employee performance. Procedia-Social and Behavioral Sciences, 133, 106-115

6. Baloch, Q. B. (2009). Effects of job satisfaction on employees motivation \& turn over intentions. Journal of Managerial Sciences, 2(1), 1-21

7. Baloch, Q. B., Latif, F., \& Azam, N. (2016). Relationship Between Psychological Capital and Counterproductive Work Behavior. Peshawar Journal of Psychology and Behavioral Sciences (PJPBS), 2(1), 127-143

8. Bashir, U., \& Ismail Ramay, M. (2010). Impact of stress on employees' job performance: A study on banking sector of Pakistan. Bashir, U., \& Ramay, MI (2010). Impact Of Stress On Employees Job Performance A Study On Banking Sector Of Pakistan. International Journal of Marketing Studies, 2(1), $122-126$

9. Bender, D. S., Morey, L. C., \& Skodol, A. E. (2011). Toward a model for assessing level of personality functioning in DSM-5, part I: A review of theory and methods. Journal of Personality Assessment, 93(4), 332-346

10. Bobek, D., Zaff, J., Li, Y., \& Lerner, R. M. (2009). Cognitive, emotional, and behavioral components of civic action: Towards an integrated measure of civic engagement. Journal of Applied Developmental Psychology, 30(5), 615-627

11. Bourne, C., \& Watts, F. (2011). Conceptualizations of spiritual healing: Christian and secular. Spiritual Healing Scientific and Religious Perspective

12. Brown, A. D., Kouri, N. A., Rahman, N., Joscelyne, A., Bryant, R. A., \& Marmar, C. R. (2016). Enhancing self-efficacy improves episodic future thinking and social-decision making in combat veterans with posttraumatic stress disorder. Psychiatry Research, 242, 19-25

13. Cadwallader, S., Jarvis, C. B., Bitner, M. J., \& Ostrom, A. L. (2010). Frontline employee motivation to participate in service innovation implementation. Journal of the Academy of Marketing Science, 38(2), 219-239

14. Campbell, J. P. (1994). Alternative models of job performance and their implications for selection and classification. Personnel selection and classification, 35

15. Canda, E. R., Furman, L. D., \& Canda, H. J. (2019). Spiritual diversity in social work practice: The heart of helping. USA: Oxford University Press

16. Ciocca, G., Carosa, E., Stornelli, M., Limoncin, E., Gravina, G. L., lannarelli, R. ... Jannini, E. A. (2015). Post-traumatic stress disorder, coping strategies and type 2 diabetes: psychometric assessment after L'Aquila earthquake. Acta diabetologica, 52(3), 513-521

17. Corrarino, J. E. (2008). Disaster-related mental health needs of women and children. MCN, The American Journal of Maternal/Child Nursing, 33(4), 242-248) 
18. Elbogen, E. B., Johnson, S. C., Wagner, H. R., Sullivan, C., Taft, C. T., \& Beckham, J. C. (2014). Violent behaviour and post-traumatic stress disorder in US Iraq and Afghanistan veterans. The British Journal of Psychiatry, 204(5), 368-375

19. Garg, N. (2020). Promoting organizational performance in Indian insurance industry: The roles of workplace spirituality and organizational citizenship behaviour. Global Business Review, 21(3), 834849

20. Gates, D. M., Gillespie, G. L., \& Succop, P. (2011). Violence against nurses and its impact on stress and productivity. Nurs Econ, 29(2), 59-66

21. Ghazali, S. R. (2004). Posttraumatic stress disorder, emotional intelligence, and gender differences among refugee children from the Middle East (Doctoral dissertation, Union Institute and University)

22. Grieger, T. A., Cozza, S. J., Ursano, R. J., Hoge, C., Martinez, P. E., Engel, C. C., \& Wain, H. J. (2006). Posttraumatic stress disorder and depression in battle-injured soldiers. American Journal of Psychiatry, 163(10), 1777-1783

23. Guillory, W. A. (2000). Spirituality in the workplace. Salt Lake City, UT: Innovations International

24. Hanif, F., Naqvi, S. R., \& Hussain, K. (2015). The role of employee engagement in work-related outcomes. Advances in Economics and Business, 3(6), 204-214

25. Hassan, M., Nadeem, B., A. and, \& Akhter, A. (2016). Impact of workplace spirituality on job satisfaction: Mediating effect of trust. Cogent Business \& Management, 3(1), 1189

26. Hayes, A. F. (2017). Introduction to mediation, moderation, and conditional process analysis: $A$ regression-based approach. Guilford publications

27. Houghton, J. D., Neck, C. P., \& Krishnakumar, S. (2016). The what, why, and how of spirituality in the workplace revisited: A 14-year update and extension. Journal of Management, Spirituality \& Religion, 13(3), 177-205

28. Iqbal, N., Anwar, S., \& Haider, N. (2015). Effect of leadership style on employee performance. Arabian Journal of Business and Management Review, 5(5), 1-6

29. Janke, K., Driessen, M., Behnia, B., Wingenfeld, K., \& Roepke, S. (2018). Emotional intelligence in patients with posttraumatic stress disorder, borderline personality disorder and healthy controls. Psychiatry research, 264, 290-296

30. Kalantari, M. R., \& Khalili, R. N. (2018). The Relationship between Spirituality in Workplace, Organizational Commitment and Professional Ethics among Girl's Senior High School Teachers.Iranian Journal of Psychiatry and Behavioral Sciences, 12(2)

31. Kearney, D. J., Malte, C. A., McManus, C., Martinez, M. E., Felleman, B., \& Simpson, T. L. (2013). Loving-kindness meditation for posttraumatic stress disorder: A pilot study. Journal of Traumatic Stress, 26(4), 426-434

32. Kent, B. V. (2019). Religion/spirituality and gender-differentiated trajectories of depressive symptoms age 13-34. Journal of religion and health,1-18 
33. Kent, B. V., Stroope, S., Kanaya, A. M., Zhang, Y., Kandula, N. R., \& Shields, A. E. (2020). Private religion/spirituality, self-rated health, and mental health among US South Asians. Quality of Life Research, 29(2), 495-504

34. Kessler, R. C., Sonnega, A., Bromet, E., Hughes, M., \& Nelson, C. B. (1995). Posttraumatic stress disorder in the National Comorbidity Survey. Archives of general psychiatry, 52(12), 1048-1060

35. Kessler, R. C. (2000). Posttraumatic stress disorder: the burden to the individual and to society. The Journal of clinical psychiatry

36. Khalid, A., Pan, F., Li, P., Wang, W., \& Ghaffari, A. S. (2020). The impact of occupational stress on job burnout among bank employees in Pakistan, with psychological capital as a mediator. Frontiers in public health, 7, 410

37. Kim, M., \& Kim, J. (2020). Corporate social responsibility, employee engagement, well-being and the task performance of frontline employees. Management Decision

38. Kintzle, S., \& Castro, C. A. (2018). Examining veteran transition to the workplace through military transition theory. Occupational stress and well-being in military contexts. Emerald Publishing Limited

39. Kovacs, M., \& Garrison, B. (1985). Hopelessness and eventual suicide: a 10-year prospective study of patients hospitalized with suicidal ideation. American journal of Psychiatry, 1(42), 559-563

40. Kulka, R. A., Schlenger, W. E., Fairbank, J. A., Hough, R. L., Jordan, B. K., Marmar, C. R., \& Weiss, D. S. (1990). Trauma and the Vietnam war generation: Report of findings from the National Vietnam Veterans Readjustment Study. Brunner/Mazel

41. Levy, N. A. (1945). Personality disturbances in combat fliers. Josiah. Macy Jr. Foundation

42. Matthews, G., Zeidner, M., \& Roberts, R. D. (2017). Emotional intelligence, health, and stress. The handbook of stress and health: A guide to research and practice, 312-326

43. Miller, L., Wickramaratne, P., Gameroff, M. J., Sage, M., Tenke, C. E., \& Weissman, M. M. (2012). Religiosity and major depression in adults at high risk: a ten-year prospective study. American Journal of Psychiatry, 169(1), 89-94

44. Milliman, J., Gatling, A., \& Kim, J. S. (2018). The effect of workplace spirituality on hospitality employee engagement, intention to stay, and service delivery. Journal of Hospitality and Tourism Management, 35, 56-65

45. MacLean, M. B., Van Til, L., \& Poirier, A. (2017). Pre-and post-release income of Regular Force Veterans: Life after Service Studies 2016. Charlottetown, PE: Veterans Affairs Canada. Research Directorate Technical Report

46. Mcleay, S. C., Harvey, W. M., Romaniuk, M. N., Crawford, D. H., Colquhoun, D. M., Young, R. M., \& Strakosch, C. R. (2017). Physical comorbidities of post-traumatic stress disorder in Australian Vietnam War veterans. Medical Journal of Australia, 206(6), 251-257

47. Meyer, E. C., La Bash, H., DeBeer, B. B., Kimbrel, N. A., Gulliver, S. B., \& Morissette, S. B. (2019). Psychological inflexibility predicts PTSD symptom severity in war veterans after accounting for established PTSD risk factors and personality. Psychological Trauma: Theory, Research, Practice, and Policy, 11(4), 383 
48. Milliman, J., Gatling, A., \& Kim, J. S. (2018). The effect of workplace spirituality on hospitality employee engagement, intention to stay, and service delivery. Journal of Hospitality and Tourism Management, 35, 56-65

49. Mobbs, M. C., \& Bonanno, G. A. (2018). Beyond war and PTSD: The crucial role of transition stress in the lives of military veterans. Clinical psychology review, 59, 137-144

50. Murphy, K. R. (1989). Is the relationship between cognitive ability and job performance stable over time? Human performance, 2(3), 183-200

51. Newsome, B. (2003). The myth of intrinsic combat motivation. The Journal of Strategic Studies, 26(4), 24-46

52. Parry-Jones, B. L., Vaughan, F. L., \& Cox, M., W (2006). Traumatic brain injury and substance misuse: a systematic review of prevalence and outcomes research (1994-2004). Neuropsychological rehabilitation, 16(5), 537-560

53. Qamar, F. M., \& Baloch, Q. B. (2011). Job satisfaction and performance: A comparative study of private and public sector hospitals. Abasyn Journal of Social Sciences, 4(1), 56-69

54. Seal, K. H., Bertenthal, D., Miner, C. R., Sen, S., \& Marmar, C. (2007). Bringing the war back home: Mental health disorders among 103788 US veterans returning from Iraq and Afghanistan seen at Department of Veterans Affairs Facilities. Archives of internal medicine, 167(5), 476-482

55. Schnurr, P. P., Lunney, C. A., Bovin, M. J., \& Marx, B. P. (2009). Posttraumatic stress disorder and quality of life: Extension of findings to veterans of the wars in Iraq and Afghanistan. Clinical psychology review, 29(8), 727-735

56. Sharma, V., Marin, D. B., Koenig, H. K., Feder, A., lacoviello, B. M., Southwick, S. M., \& Pietrzak, R. H. (2017). Religion, spirituality, and mental health of US military veterans: Results from the National Health and Resilience in Veterans Study. Journal of affective disorders, 217, 197-204

57. Shuck, B., Twyford, D., Reio Jr, T. G., \& Shuck, A. (2014). Human resource development practices and employee engagement: Examining the connection with employee turnover intentions. Human Resource Development Quarterly, 25(2), 239-270

58. Silke, A., \& Brown, K. (2016). 'Radicalization': The Transformation of Modern Understanding of Terrorist Origins, Psychology and Motivation. In State, Society and National Security: Challenges and Opportunities in the 21st Century (pp. 129-150)

59. Simpson, J., \& Sariol, A. M. (2019). Squared away: Veterans on the board of directors. Journal of Business Ethics, 160(4), 1035-1045

60. Singh, Y., \& Sharma, R. (2012). Relationship between general intelligence, emotional intelligence, stress levels and stress reactivity. Annals of neurosciences, 19(3), 107

61. Tsai, J., Harpaz-Rotem, I., Pietrzak, R. H., \& Southwick, S. M. (2012). The role of coping, resilience, and social support in mediating the relation between PTSD and social functioning in veterans returning from Iraq and Afghanistan. Psychiatry: Interpersonal \& Biological Processes, 75(2), 135-149

62. Verhage, A., Noppe, J., Feys, Y., \& Ledegen, E. (2018). Force, stress, and decision-making within the Belgian police: the impact of stressful situations on police decision-making. Journal of Police and 
Criminal Psychology, 33(4), 345-357

63. Vijayan, M. (2017). Impact of job stress on employees job Performance in aavin, coimbatore. Journal of Organisation and Human Behaviour, 6(3), 21

64. Vogt, D., Smith, B. N., Fox, A. B., Amoroso, T., Taverna, E., \& Schnurr, P. P. (2017). Consequences of PTSD for the work and family quality of life of female and male US Afghanistan and Iraq War veterans. Social psychiatry and psychiatric epidemiology, 52(3), 341-352

65. Wagner, I. I. I., J. A (1994). Participation's effects on performance and satisfaction: A reconsideration of research evidence. Academy of management Review, 19(2), 312-330

66. Watts, F. (Ed.). (2011). Spiritual healing: Scientific and religious perspectives. Cambridge University Press

67. Weathers, F. W., Litz, B. T., Keane, T. M., Palmieri, P. A., Marx, B. P., \& Schnurr, P. P. (2013). The ptsd checklist for dsm-5 (pcl-5). Scale available from the National Center for PTSD at www. ptsd. va. gov, 10

68. Weaver, A. J., Flannelly, L. T., Garbarino, J., Figley, C. R., \& Flannelly, K. J. (2003). A systematic review of research on religion and spirituality in the Journal of Traumatic Stress: 1990-1999. Mental Health, Religion \& Culture, 6(3), 215-228

69. Weiss, D. S., Marmar, C. R., Schlenger, W. E., Fairbank, J. A., Jordan, K., Hough, B., R. L., \& Kulka, R. A. (1992). The prevalence of lifetime and partial post-traumatic stress disorder in Vietnam theater veterans. Journal of traumatic stress, 5(3), 365-376

70. Wright, D. G., \& Bond, D. D. (1945). Notes on Men and Groups Under Stress of Combat: For the Use of Flight Surgeons in Operational Units How Can the Flight Surgeon Better Treat Anxiety? Josiah Macy Jr. Foundation

71. Worden, J. W. (2018). Grief counseling and grief therapy: A handbook for the mental health practitioner. Springer publishing Company

72. Yager, J., \& Kay, J. (2020). Autotraumatic stress disorders: Posttraumatic stress disorder variants when the victim bears responsibility for the trauma. The Journal of Nervous and Mental Disease, 208(12), 947-952

73. Zatzick, D. F., Marmar, C. R., Weiss, D. S., Browner, W. S., Metzler, T. J., Golding, J. M., \& Wells, K. B. (1997). Posttraumatic stress disorder and functioning and quality of life outcomes in a nationally representative sample of male Vietnam veterans. American Journal of Psychiatry, 154(12), 16901695

74. Zatzick, D. F., Weiss, D. S., Marmar, C. R., Metzler, T. J., Wells, K., Golding, J. M., \& Browner, W. S. (1997). Post-traumatic stress disorder and functioning and quality of life outcomes in female Vietnam veterans. Military Medicine, 162(10), 661-665

\section{Declarations}

We all authors declared following: 
a. All ethical standards were truly compiled during the research by all authors.

b. The research is not funded by any outside funding agency.

C. There is no conflict of interest to be reported

d. We acknowledge the support of military hospitals administration in facilitating our data collection process.

It is certified that all ethical requirements were fulfilled while investigating the participants and they were briefed about the purpose of research. All of the participants were duly informed and they willingly responded to our questionnaires served to them. Each questionnaire was filled by them that reflects their are informed consent.

\section{Tables}

Table No. 1: Validity and Reliability Values of the Instrument

\begin{tabular}{|c|c|c|}
\hline Instrument/ Variable Source & No. of item & Cronbach Alpha \\
\hline PTSD & 20 & 0.776 \\
\hline Spirituality & 16 & 0.725 \\
\hline Employee PP & 05 & 0.80 \\
\hline
\end{tabular}

Table No. 2: Descriptive Analysis

\begin{tabular}{lccccc}
\hline & N & Minimum Maximum & Mean & Std. Deviation \\
\hline PTSD & 97 & 2.00 & 4.50 & 2.996 & .46360 \\
PERFOMACE & 97 & 1.00 & 2.60 & 1.5072 & .35007 \\
SPIRTUALITY 97 & 1.06 & 3.38 & 2.5567 & .49420 \\
\hline
\end{tabular}

Table No. 3: Correlation Analysis

\begin{tabular}{lcccc}
\hline & Age & PTSD PERFOMACE & SPIRTUALITY \\
\hline Age & 1 & & & \\
PTSD & $.227^{*}$ & 1 & & \\
PERFORMANCE & .030 & $-.332^{* *}$ & 1 & \\
SPIRTUALITY & .067 & $-.494^{* *}$ & $.487^{* *}$ & 1 \\
\hline
\end{tabular}

Table: 4: $\quad$ Model Summary 


\begin{tabular}{|c|c|c|c|c|c|c|c|c|}
\hline $\mathrm{R}$ & $\mathrm{R} \mathrm{Sq}$ & MSE & Df1 & Df2 & $\mathrm{P}$ & & & \\
\hline .5034 & .2534 & .0944 & 6.6351 & 3.0000 & 93.0000 & & .0004 & \\
\hline & Coeff & $\mathrm{SE}$ & $\mathrm{T}$ & $\mathrm{P}$ & LLCI & & ULCI & \\
\hline constant & 1.4993 & .0344 & 43.5589 & .0000 & 1.4310 & & 1.5677 & \\
\hline SP & .2805 & .0847 & 3.3115 & .0003 & & .1123 & & .4486 \\
\hline PTSD & -.0708 & .0818 & 5.8660 & .0007 & .0916 & & .2332 & \\
\hline int_1 & .0706 & .1363 & 6.5181 & .0006 & .2001 & & .3414 & \\
\hline
\end{tabular}

Interactions

Conditional effect of $\mathrm{X}$ on $\mathrm{Y}$ at values of the moderator(s)

\begin{tabular}{lllllll}
\hline SP & Effect & se & T & P & LLCI & ULCI \\
\hline-.4942 & .0359 & .1067 & .3366 & .7372 & -.1759 & .2477 \\
& & & & & & \\
.0000 & .0708 & .0818 & 3.8660 & .0003 & .0916 & .2332 \\
.4942 & .1057 & .1052 & 6.0045 & .0007 & .1033 & .3147 \\
\hline
\end{tabular}

\section{Figures}

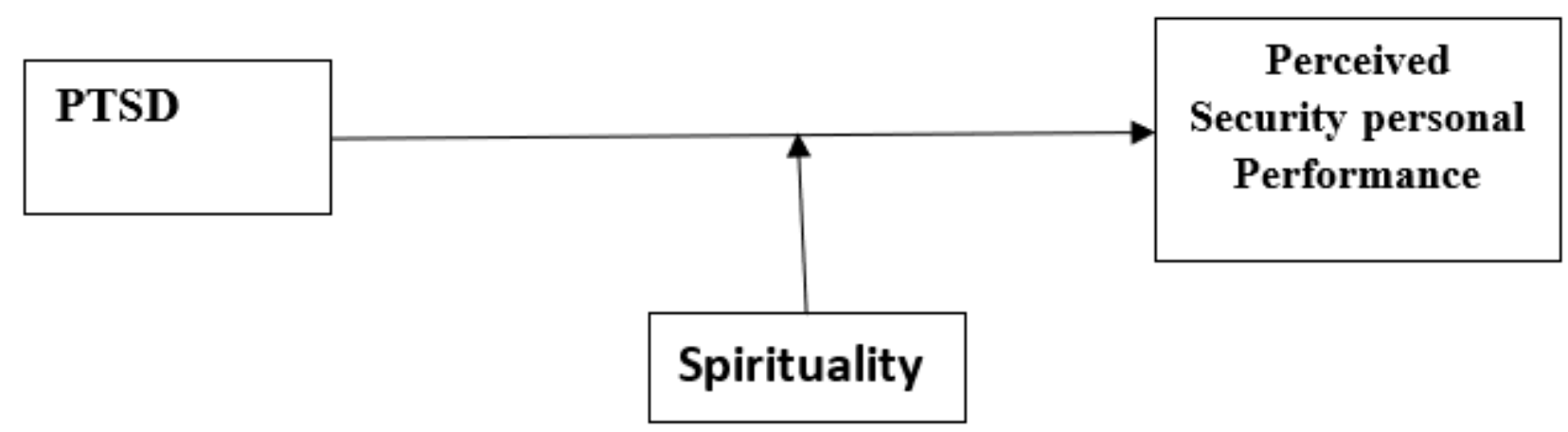

Figure 1

Conceptual Framework 